\title{
Expression of pAkt affects p53 codon 72 polymorphism-based prediction of response to radiotherapy in nasopharyngeal carcinoma
}

Xiaoxue Xie ${ }^{1+}$, Hui Wang ${ }^{1+}$, Hekun Jin ${ }^{1}$, Shuyu Ouyang ${ }^{1}$, Jumei Zhou ${ }^{1}$, Jun $\mathrm{Hu}^{3}$, Xuping $\mathrm{Xi}^{1}$, Junming Luo ${ }^{1}$, Yingying Zhang ${ }^{2}$ and Bingqiang $\mathrm{Hu}^{1 *}$

\begin{abstract}
Background: Codon 72 (Arg/Pro), the most frequently studied single nucleotide polymorphism (SNP) of p53 to date, is associated with the ability of the gene to induce cell apoptosis. The PI3K/Akt pathway plays an essential role in the transcriptional activation function of p53, and is an important factor in radiotherapy resistance. The present study was designed to evaluate the prediction of response to radiotherapy based on p53 codon 72 SNP and pAkt expression in biopsy specimens of locoregional nasopharyngeal carcinoma (NPC) before treatment.

Materials and methods: In total, 75 consecutive patients with locoregional NPC were enrolled. The p53 codon 72 SNP was identified from retrospectively collected paraffin-embedded biopsy specimens using Sanger sequencing. Expression patterns of p53, p21, 14-3-30, and pAkt proteins were investigated using immunohistochemical analyses. The effects of genetic polymorphisms and protein expression on progression-free survival (PFS) were evaluated using the Cox proportional hazards model, Kaplan-Meier method, and log-rank test.

Results: The p53 codon 72 Pro/Pro carriers showed lower risk of disease progression (local recurrence and distant metastases) (HR: 0.300; 95\% Cl: 0.092-0.983; $p=0.047$ ). However, this association between the p53 codon 72 polymorphism and PFS was not significant in the pAkt-positive subgroup. No association was observed between protein expression of p53, p21 or 14-3-30 and p53 codon72 polymorphisms. Notably, positive expression of p53 protein appeared to be correlated with poorer PFS among patients diagnosed as local regional lymph node metastasis $(\mathrm{N}+)$ before treatment $(p=0.032)$.

Conclusions: The p53 codon 72 Pro/Pro genotype may be an effective independent prognostic marker for better outcome in patients with locoregional NPC. Based on the current findings, we hypothesize that pAkt weakens the predictive value of p53 codon 72 SNP in NPC. A combination of positive p53 protein expression and local regional lymph node metastasis may additionally be predictive of high risk of disease progression.
\end{abstract}

Keywords: Nasopharyngeal carcinoma, p53 codon 72 polymorphism, pAkt, Radiotherapy

\section{Introduction}

Nasopharyngeal carcinoma (NPC) is an epithelial malignancy with an annual incidence of 15 to 50 cases per 100,000 individuals in Southern China [1]. The prognosis of patients with NPC in the early stages is generally favorable, although the incidence of relapse remains high

\footnotetext{
* Correspondence: bingqianghu@hotmail.com

${ }^{\dagger}$ Equal contributors

'Department of Radiation and Oncology, Hunan Provincial Tumor Hospital \& Affiliated Tumor Hospital of Xiangya Medical School, Central South University, Changsha 410013, China

Full list of author information is available at the end of the article
}

for locoregionally advanced NPC [2,3]. Radiotherapy remains the primary mode of treatment for locoregional NPC. In the present study, we focused on evaluating the predictive value of the p53 pathway in outcomes of patients with locoregional NPC in response to radiotherapy. The p53 gene is thought to be central in mediating response to commonly used cancer treatments, such as radiotherapy. Codon 72 (Arg/Pro) is the most frequently studied SNP in the p53 gene to date. The amino acid encoded by codon 72 resides in a poly proline region located between the transactivation and DNA binding

\section{Biomed Central}


domains. This proline-rich region has been shown to be critical for p53 function, particularly its ability to induce apoptosis. Numerous studies have provided evidence that the two different isoforms encoded by p53 codon 72 SNP are not functionally equivalent [4-8]. In a number of cancer types, including lung and breast, patients with the 72Pro-p53 allele appear to be more susceptible to tumor development [9-12]. However, there is no consensus regarding the correlation between treatment susceptibility and p53 polymorphism at codon 72 in cancers. For example, Vannini et al. [13] reported a significantly shorter time of disease progression and overall survival in metastatic breast cancer patients homozygous for Arg, compared to those with heterozygous Arg/Pro tumors. Conversely, Kim et al. [14] reported that Arg/Pro and Pro/ Pro genotypes of TP53 codon 72 are significantly correlated with a lower response rate to combination chemotherapy, compared to the Arg/Arg genotype in advanced gastric cancer. Results from a meta-analysis [15] showed that homozygote Arg/Arg genotype is more significantly associated with decreased risk of NPC, compared with the Pro/ Pro genotype. However, the precise relationship between the TP53 codon 72 polymorphism and clinical outcomes of NPC remains to be established.

The phosphatidylinositol-3-kinase (PI3K)/protein kinase B (Akt) pathway plays an essential role in the transcriptional activation function of p53 and consequent modulation of cell fate. Notably, EGFR-independent activation of the PI3K/Akt pathway, a common occurrence, is an important factor in radiotherapy resistance [16]. Akt is a downstream effector of PI3kinase in NPC possibly associated with aggressive tumor behavior and poor survival in patients with nasopharyngeal carcinoma [17]. The existing paradigm about the nature of interactions between the PI3kinase and p53 pathways is antagonistic, whereby pAkt inhibits p53 function in a Mdm2-dependent manner [18-20]. Under conditions where the apoptotic activity of p53 prevails, it is conceivable that the destruction of pAkt plays a role in accelerating the apoptotic process.

The relationship between p53 activation and cell fate regulation is extremely complex [21]. Boehme et al. [22] proposed a signaling cascade involving activation of DNA-PK and Akt/PKB for the regulation of p53 in response to ionizing radiation. Suvasini et al. [23] also reported an essential function of PI3-kinase and its downstream effectors, Akt/PKB-mTOR, in activating p53-mediated transcription during DNA damage. In the cell membrane, Akt is activated through phosphorylation at serine and threonine residues, and modulates the expression of several genes involved in suppression of apoptosis and cell cycle progression. The mechanism by which the DNA damage-induced PI3K/Akt pathway alters p53 phosphorylation at critical residues is not clear at present. However, reduced Lys382 acetylation in
LY294002-treated cells may be explained by the finding that p300, which acetylates p53, is activated by Akt-mediated phosphorylation [24]. Thus, the classical identification of the 'pro-survival' PI3K/Akt and 'pro-apoptotic' p53 pathways adds another layer of complexity to the outcome of NPC.

The present study was designed to evaluate prediction of response to radiotherapy on the basis of p53 codon 72 SNP and p53 pathway protein expression in locoregional nasopharyngeal carcinoma (NPC) biopsy specimens before treatment. To our knowledge, this is the first study to focus on assessing the combined prognostic effects of p53 codon 72 SNP and pAkt expression.

\section{Materials and methods \\ Patient selection}

Between January 2008 and October 2009, 75 consecutive patients with locoregional NPC at the Department of Radiation and Oncology of the Hunan provincial tumor hospital were enrolled retrospectively in this study. Patients with proven biopsy and previously untreated NPC with American Joint Committee on Cancer (AJCC)/ International Union Against Cancer (UICC) stages II, III and IV (A-B) were eligible for study. Other criteria included ages greater than 18 years, Han Chinese ethnicity, and an Eastern Cooperative Oncology Group performance status of 0 or 1 . The exclusion criteria included presence of distant metastasis and other concomitant malignant disease. The study was approved by the Clinical Research Ethics Committee of the Hunan Province Cancer Center, and written informed consent was obtained from all patients. Patient characteristics are summarized in Table 1. In total, 57 male and 18 female patients (male-to-female ratio of 3.2:1) with a median age of 45 years (range, 22-72 years) were enrolled. All patients were diagnosed as World Health Organization (WHO) Grade 2-3 NPC. Among our patient population, 16 had stage II, 44 had stage III, and 15 had stage IV (A-B) disease.

\section{Pretreatment evaluation}

All patients were evaluated using complete physical examination, fiberoptic nasopharyngoscopy, MRI of the head and neck, chest X-ray, abdominal imaging with ultrasound, and bone scan.

\section{Treatment}

Megavoltage photons (6 MV) were used to treat primary tumor and neck lymph nodes. Radiotherapy was administered five times a week at a dose of $2 \mathrm{~Gy} / \mathrm{d}$. The accumulated radiation dose to the primary tumor was 68 to $72 \mathrm{~Gy}$, 60 to 62 Gy to the involved areas of the neck, and 50 Gy to uninvolved areas. Concurrent chemoradiotherapy, specifically, DDP $\left(100 \mathrm{mg} / \mathrm{m}^{2}\right)$ on days 1,22 , and 43 during radiotherapy, was administered to 39 patients. 
Table 1 Patient demographics and treatment characteristics

\begin{tabular}{lr}
\hline Characteristics & Number of patients (\%) \\
\hline Age, y & $22-72$ \\
Median age & 45 \\
Gender & $57(76.0)$ \\
Male & $18(24.0)$ \\
Female & \\
Overall stage (AJCC) ${ }^{*}$ & $16(21.3)$ \\
II & $44(58.7)$ \\
III & $15(20.0)$ \\
IVa-b & \\
T classification ${ }^{*}$ & $42(56.0)$ \\
T1-2 & $33(44.0)$ \\
T3-4 & \\
N classification & \\
No & $16(21.3)$ \\
N1-3 & $59(78.7)$ \\
Concurrent chemotherapy & \\
No & $36(48.0)$ \\
Yes & $39(52.0)$ \\
Adjuvant chemotherapy & \\
No & $35(46.7)$ \\
Yes & $40(53.3)$ \\
\hline Ameican Jont Commtte & \\
\hline
\end{tabular}

"American Joint Committee on Cancer/International Union Against Cancer staging system.

\section{End points}

The primary end point for the study was progressionfree survival (PFS), defined as the time from the day of enrollment to the date of first documentation of relapse categorized as locoregional (primary site or regional nodes) failure, distant metastases or last follow-up visit.

\section{Sample preparation, DNA extraction and quantification of DNA yield}

From each sample, eight $10 \mu \mathrm{m}$ tissue sections were deparaffinized using xylene and ethanol. Specimens were digested with proteinase $\mathrm{K}$ for $24 \mathrm{~h}$ at $55^{\mathrm{C}}$. Subsequently, the enzyme was inactivated by boiling the samples for 10 min prior to mixing with absolute ethyl alcohol. After purification with ion-exchange columns, genomic DNA was stored at $-20^{C}$ before use.

\section{DNA amplification and genotyping procedures}

Nested PCR method was used to amplify specific fragments. The PCR reaction was performed in three steps: 5 min at $95^{\mathrm{C}}$, followed by 35 cycles of $30 \mathrm{~s}$ at $95^{\mathrm{C}}, 30 \mathrm{~s}$ at $55^{\mathrm{C}}$, and $40 \mathrm{~s}$ at $72^{\mathrm{C}}$, and finally, $10 \mathrm{~min}$ at $72^{\mathrm{C}}$. Prior to Sanger sequencing, amplified products were identified by electrophoresis using BigDye Terminator v3.1 chemistry (Life Technologies, Carlsbad, CA) on an Applied Biosystems 3130XL Genetic Analyzer. All PCR reactions and sequencing analyses were performed twice to confirm the results.

\section{Immunohistochemical studies}

Immunohistochemistry (IHC) was performed on sections of 75 NPC tissues using standard techniques. Tissue sections were deparaffinized in xylene, rehydrated in a graded ethanol series, and treated with an antigen retrieval solution (10 mmol/L sodium citrate buffer, pH 6.0). Next, sections were incubated with mouse anti-human p53 antibody (1:200 dilution) overnight at $4^{\mathrm{C}}$ and 1:1,000 diluted biotinylated secondary antibody, followed by avidin-biotin peroxidase complex (DAKO, Carpinteria, CA), according to the manufacturer's instructions. Finally, tissue sections were treated with 3', 3'-diaminobenzidine (Sigma) until the development of brown color, and counterstained with Harris modified hematoxylin. In negative controls, primary antibodies were omitted. The procedure for staining pAkt, p21, and 14-3-3 $\sigma$ was similar to that for p53 IHC staining, except that the anti-p53 antibody was replaced with anti-pAkt (Thr308)(Santa Cruz Biotechnology, Inc.), anti-p21(ZSGB-BIO), and anti-14-3-3 $\sigma$ (Abcam) antibodies, respectively. Sections were blindly evaluated by two investigators in an effort to provide a consensus on staining patterns. A semiquantitative scoring criterion for immunohistochemistry was used in which both staining intensity and positive areas were recorded according to the method of Hara et al. [25]. At least 10 high-power fields were selected randomly, and $>1,000$ cells counted for each section. Staining intensity was graded on the following scale: 0: no staining, $1+$ : mild staining, $2+$ : moderate staining, and 3+: intense staining. The area of staining was scored as follows: 0: no staining in any microscopic field, $1+:<30 \%$ of tissue stained positive, $2+$ : between $30 \%$ and $60 \%$ stained positive, and $3+:>60 \%$ stained positive. The minimum score, when summed (extension+ intensity), was 0 , and the maximum score was 6 . For $14-3-3 \sigma$ and pAkt, a combined staining score (extension+ intensity) of $\leq 3$ was considered negative (low staining), and that between 4 and 6 considered positive. For p53 and p21, a combined staining score (extension+ intensity) of $\leq 4$ was considered negative (low staining), and that between 5 and 6 considered positive. Representative results of p53, p21, pAkt, and 14-3-3б immunohistochemistry are shown in Figure 1.

\section{Follow-up studies}

The follow-up analysis was completed on October 31, 2012, with a median follow-up of 25 (range, 5-46) months. After completion of treatment, patients were followed up at least every three months during the first years and every six months thereafter until disease progression (recurrence or 


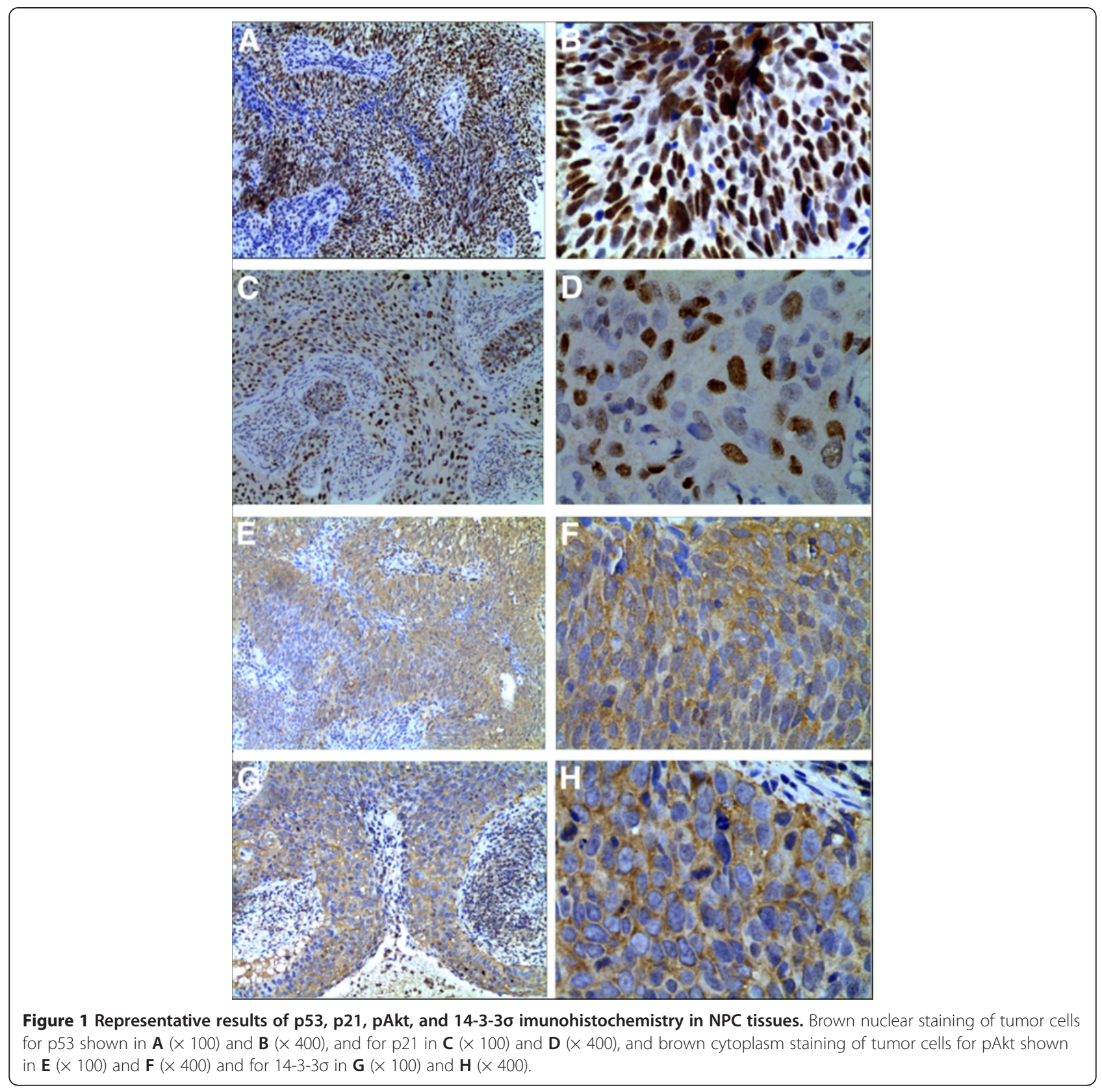

distant metastases). All local recurrences were diagnosed based on fiberoptic endoscopy and biopsy and/or MRI of the nasopharynx and the skull base showing progressive bone erosion and/or soft tissue swelling. Regional recurrences were diagnosed by clinical examination of the neck and, in doubtful cases, fine needle aspiration or MRI of the neck. Distant metastases were diagnosed on the basis of clinical symptoms, physical examination and imaging methods, including chest radiography, abdominal ultrasound, whole body bone scan, CT scan, and MRI. During follow-up, 22 (29.3\%) patients had locoregional relapse and $21(28.0 \%)$ had distant metastasis. No patients died during follow-up. The 3-year PFS rate was 42.7\% (32/75).

\section{Statistical analysis}

The correlation between IHC results and p53 codon 72 genotypes was evaluated using Pearson $\chi^{2}$ test. The Hardy-Weinberg equilibrium was tested using a goodness-of-fit $X^{2}$ test with one degree of freedom. The Kaplan-Meier method was adopted to estimate survival curves, and the log-rank test used to compare patient survival times between subgroups. Multivariate analyses using Cox regression were employed to assess the importance of clinical variables, with adjustment for age, gender, $\mathrm{T}$ classification, $\mathrm{N}$ classification, and concurrent chemotherapy. Analyses were carried out using the statistical software package SPSS 17.0 (SPSS). All statistical 


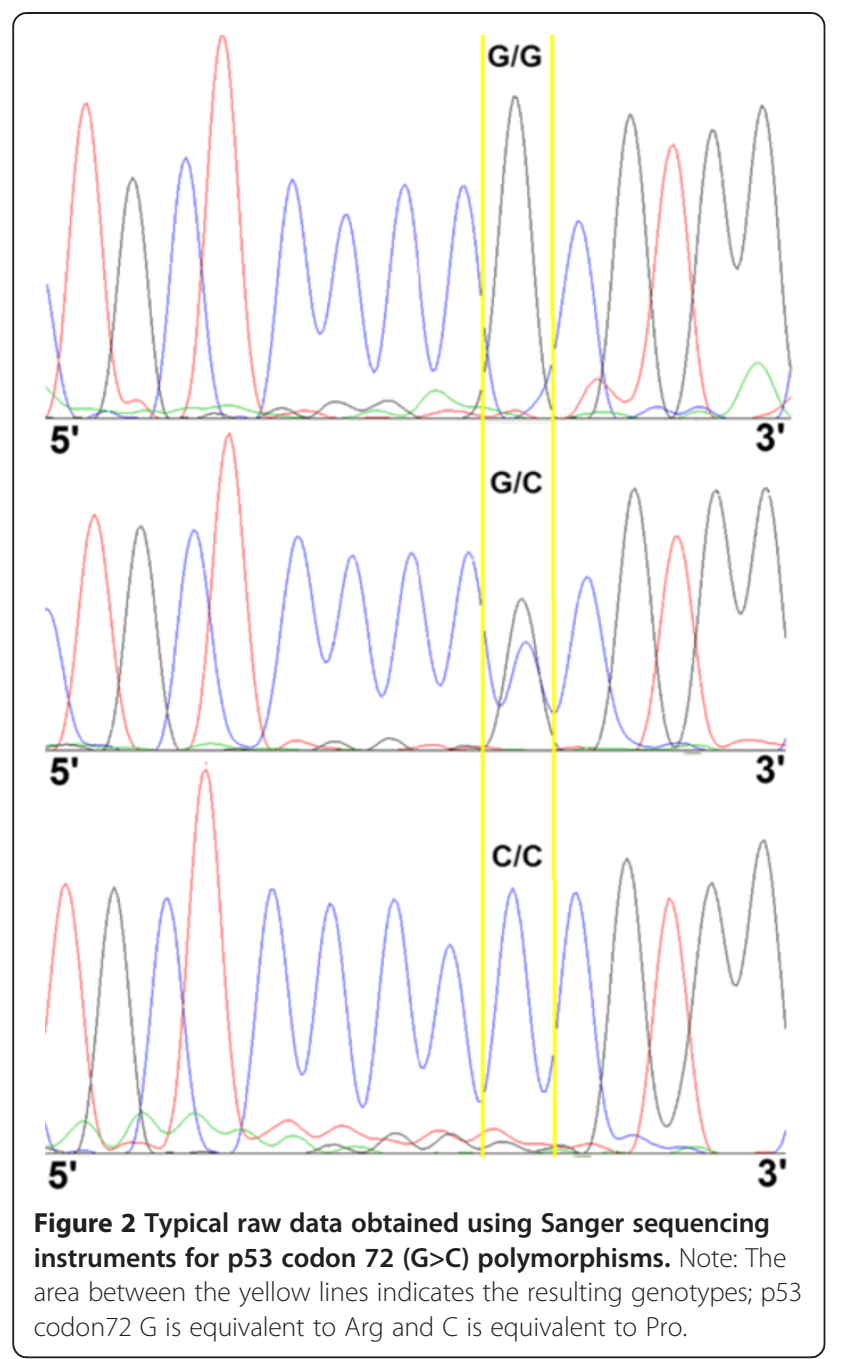

tests were two-sided, and a value of $p<0.05$ considered statistically significant.

\section{Results}

The p53 codon72 polymorphism was clearly distinguished via Sanger sequencing. Typical sequencing peak diagrams are depicted in Figure 2. The frequency of the Arg allele was 0.23 , fulfilling the Hardy-Weinberg distribution. We observed no significant association between the p53 codon72 SNP and clinical variables (Table 2). Expression
Table 3 Association between p53 codon 72 genotypes and p53/p21/14-3-36 protein expression (Chi-square analysis)

\begin{tabular}{cccccc}
\hline & & \multicolumn{3}{c}{ p53 codon 72 genotypes } & \\
\cline { 3 - 5 } \multicolumn{2}{c}{ Protein expression } & Arg/Arg & Arg/Pro & Pro/Pro & p \\
\hline p53 & Positive & 20 & 16 & 6 & 0.423 \\
& Negative & 12 & 13 & 6 & \\
\multirow{2}{*}{ p21 } & Positive & 8 & 5 & 3 & 0.748 \\
& Negative & 23 & 25 & 9 & \\
\multirow{2}{*}{$14-3-30$} & Positive & 18 & 17 & 3 & 0.100 \\
& Negative & 13 & 13 & 9 & \\
\hline
\end{tabular}

patterns of p53, p21, and 14-3-3 $\sigma$ were not affected by p53 codon72 polymorphisms (Table 3 ).

For clinical variables, only $\mathrm{T}$ classification was associated significantly with the time to disease progression (Figure 3 ) $(p=0.005)$. However, both T (HR: 2.683 ; $95 \%$ CI: 1.430 5.032; $\boldsymbol{p}=\mathbf{0 . 0 0 2}$ ) and N (HR: 1.778; 95\% CI: 1.196-2.644; $\boldsymbol{p}=\mathbf{0 . 0 0 4}$ ) classifications were significantly correlated with 3year PFS rates after adjustment for age $(<45$ and $\geq 45$ years), gender (male and female), and concurrent chemotherapy (yes or no) (Table 4). Hazard ratios (HR) for disease progression (distant metastases and local recurrence) were significantly lower for Pro/Pro p53 codon 72 carriers after adjustment (HR: 0.300; 95\% CI: 0.092-0.983; $\boldsymbol{p}=\mathbf{0 . 0 4 7}$ ) (Table 4). However, no overall association was evident between p53, p21 or $14-3-3 \sigma$ protein expression and PFS (Table 4).

As shown in Figure 4A, positive p53 protein expression was correlated with poorer PFS in a subgroup of patients diagnosed with lymph node metastasis $(\mathrm{N}+)$ before initial treatment $(p=0.032)$. Kaplan-Meier PFS curves were obtained according to p53 codon 72 SNP and p53 expression, respectively (Figure 4). Patients carrying the Pro/Pro p53 codon 72 SNP displayed a longer time to disease progression than those with other polymorphic variants $(p=0.043$, Figure $4 \mathrm{~B})$. This result was significant in the pAkt-negative $(p=0.034$, Figure $4 \mathrm{C})$, but not the pAkt-positive subgroup ( $p=0.388$, Figure 4D).

Results of analysis of the combined effects of the p53 codon72 polymorphism and pAkt protein expression on risk of disease progression (local recurrence and distant metastases) are shown in Table 5. According to log-rank

Table 2 Correlation of p53 codon 72 genotypes with clinical variables (Chi-square analysis)

\begin{tabular}{|c|c|c|c|c|c|c|}
\hline \multicolumn{2}{|c|}{ Arg/Arg } & \multicolumn{2}{|c|}{ Arg/Pro } & \multicolumn{2}{|c|}{ Pro/Pro } & \multirow[t]{2}{*}{$p$} \\
\hline T1-2 & T3-4 & T1-2 & T3-4cp & T1-2 & T3-4 & \\
\hline $17(40.48 \%)$ & $16(48.48 \%)$ & 19(45.24\%) & $11(33.33 \%)$ & $6(14.29 \%)$ & 6(18.18\%) & 0.810 \\
\hline No & $\mathrm{N}+$ & NO & $\mathrm{N}+$ & No & $\mathrm{N}+$ & \\
\hline $8(50 \%)$ & $25(42.37 \%)$ & $5(31.25 \%)$ & $25(42.37 \%)$ & $3(18.75 \%)$ & $9(15.25 \%)$ & 0.842 \\
\hline Stage II & Stage III-IV & Stage II & Stage III-IV & Stage II & Stage III-IV & \\
\hline 7(43.75\%) & $26(44.7 \%)$ & 7(43.75\%) & 23(38.98\%) & $2(12.5 \%)$ & $10(16.95 \%)$ & 0.842 \\
\hline
\end{tabular}




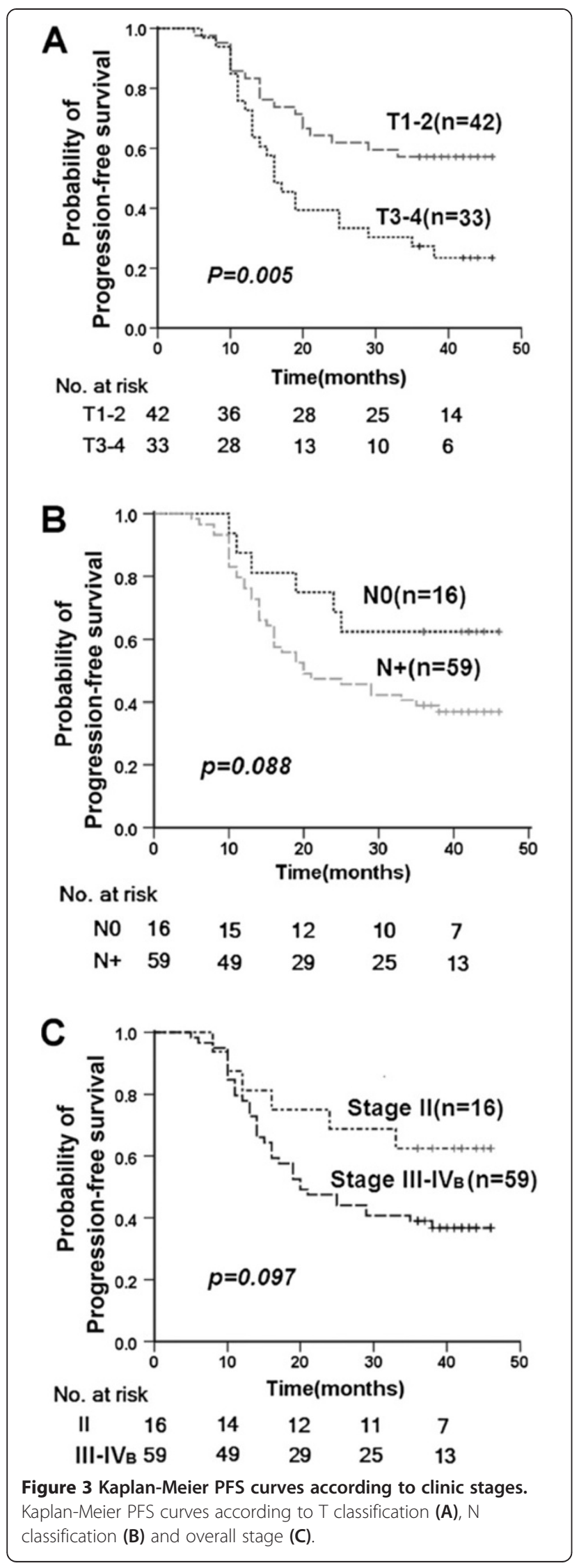

Table 4 Multivariate analysis of progress-free survival (PFS) using the Cox proportional hazards model

\begin{tabular}{|c|c|c|c|c|}
\hline Variables & Subgroups & HR & $95 \% \mathrm{Cl}$ & $p$ \\
\hline T classification & T3-4 vs. T1-2 & 2.683 & $1.430-5.032$ & 0.002 \\
\hline N classification & $\mathrm{N}+$ vs. NO & 1.778 & $1.196-2.644$ & 0.004 \\
\hline $\begin{array}{l}\text { p53 codon } \\
72 \text { genotype }\end{array}$ & C/C vs. G/C+ & 0.300 & $0.092-0.983$ & 0.047 \\
\hline p53 protein & Positive vs. Negative & 1.714 & $0.893-3.291$ & 0.105 \\
\hline pAkt protein & Positive vs. Negative & 1.025 & $0.542-1.938$ & 0.939 \\
\hline p21 protein & Positive vs. Negative & 0.745 & $0.338-1.641$ & 0.465 \\
\hline$-3-3 \sigma$ protein & Positive vs. Negative & 1.440 & $0.764-2.711$ & 0.259 \\
\hline
\end{tabular}

Abbreviations: $H R$, hazard ratio; $\mathrm{Cl}$, confidence interval.

Note: p53 codon $72 \mathrm{G}$ is equivalent to $\mathrm{Arg}$ and $\mathrm{C}$ is equivalent to Pro.

analysis, subjects carrying the p53 codon 72 Pro/Pro genotype displayed significantly longer time to disease progression, compared to those with other genotypes, in the pAkt-negative subgroup $(\boldsymbol{p}=\mathbf{0 . 0 3 4})$. However, this result was not significant upon assessment with the Cox proportional hazards model $(p=0.191)$. Moreover, no significant association between the p53 codon 72 polymorphism and PFS was observed in the pAktpositive subgroup.

\section{Discussion}

In the present study, patients carrying p53 codon 72 Pro/Pro displayed better PFS than those with other polymorphisms. Multivariate analysis of the three-year PFS rate with both Cox proportional hazards model and log-rank analysis of time to disease progression suggested that the p53 codon72 polymorphism is an independent predictor of response to radiotherapy in nasopharyngeal carcinoma.

Pro72 and Arg72 variants are reported to differ in terms of functional activity. Specifically, the Pro72 variant possesses enhanced ability to transactivate $\mathrm{p} 21$ and induce growth arrest $[4,6,26,27]$, while the Arg72 variant demonstrates superior mitochondrial localization in tumor cell lines [5]. Interestingly, Dumont and co-workers showed that the Arg72 variant is more efficient than the Pro72 variant in inducing apoptosis. One possible mechanism underlying this greater efficiency is enhanced localization of the Arg72 variant to mitochondria [5]. In contrast, our results suggest that the p53 codon72 Pro/Pro genotype is associated with improved PFS in locoregional NPC patients. A recent study showed binding of the p 53 homolog, p73, to specific tumor-derived mutant forms of p53, which is influenced by the codon 72 polymorphism. It was proposed that several common mutants of mtp53codon72-Arg bind with greater affinity to p73, thereby inhibiting its ability to induce apoptosis [28-31]. However, the p53 gene is rarely mutated in nasopharyngeal carcinoma [32]. Additionally, the Arg72 variant has been 

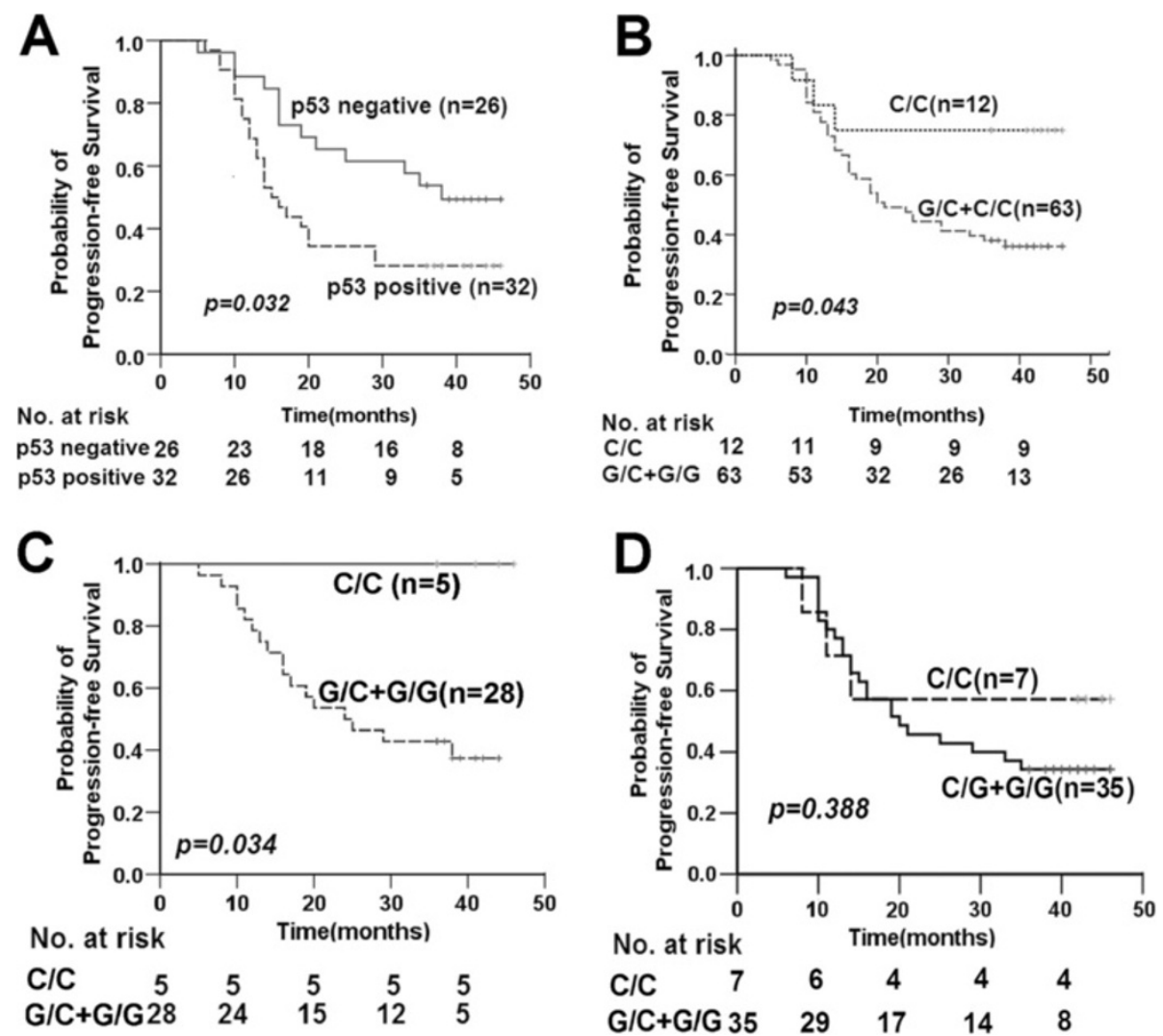

Figure 4 Kaplan-Meier PFS curves according to P53. Kaplan-Meier PFS curves according to protein expression of p53 (positive vs. negative) among patients diagnosed as local regional lymph node metastasis (A); Kaplan-Meier PFS curves according to dominant model of p53 codon 72 SNPs (C/C vs. G/C+G/G) (B); Kaplan-Meier PFS curves according to dominant model of p53 codon 72 SNPs (C/C vs. G/C+G/G) in the pAktnegative (C) and pAkt-positive subgroups (D). Note: p53 codon72 G is equivalent to Arg and $\mathrm{C}$ is equivalent to Pro.

shown to be more susceptible to degradation by the human papillomavirus (HPV) 18 E6 protein [33]. Approximately $15-20 \%$ of head-and-neck squamous cell carcinomas (HNSCC) may be linked to HPV infection [34-36]. Accordingly, the effect of HPV on response to radiotherapy of Arg72 variant carriers in NPC requires further study. Other mechanisms should also be considered. For example, Vannini et al. [13] provided a molecular explanation for association of the Arg allele with tumor aggressiveness and treatment resistance in advanced breast cancer. The group demonstrated that lower cell death is induced under hypoxia upon transfection of the Arg allele, compared to Pro allele in vitro, which was explained by the finding that the Arg allele upregulates BCRP-I, a hypoxia response gene, that increases treatment resistance. While the precise molecular mechanisms underlying these differences in apoptosis merit further study, these observations suggest that determination of the patient genotype at p53 codon 72 may aid in identifying patient populations with poorer response to radiotherapy.

The prognostic value of p53 protein expression in NPC has been investigated, but the results obtained to date are controversial. The groups of Faccioli [37], Genc [38], Shi [39], and Tsai [40] reported that p53 overexpression is not

Table 5 Log-rank and proportional hazard analysis (Cox method) of progression-free survival (PFS) in relation to p53 codon 72 genotypes and pAkt protein expression

\begin{tabular}{|c|c|c|c|c|c|c|}
\hline \multirow{2}{*}{$\begin{array}{l}\text { p53 codon } 72 \\
\text { polymorphism }\end{array}$} & \multirow{2}{*}{$\begin{array}{c}\text { pAkt protein } \\
\text { expression }\end{array}$} & \multicolumn{2}{|c|}{ Log-rank analysis } & \multicolumn{3}{|c|}{ Cox-regression } \\
\hline & & $\begin{array}{l}\text { Mean survival } \\
\text { time(months) }\end{array}$ & $p$ & HR & $95 \% \mathrm{Cl}$ & $p$ \\
\hline $\mathrm{G} / \mathrm{G}+\mathrm{G} / \mathrm{C}$ & Positive & $24.66 \pm 2.38$ & - & 1 & reference & - \\
\hline $\mathrm{C} / \mathrm{C}$ & Positive & $29.86 \pm 6.72$ & 0.388 & 0.626 & $0.187-2.096$ & 0.447 \\
\hline $\mathrm{G} / \mathrm{G}+\mathrm{G} / \mathrm{C}$ & Negative & $25.79 \pm 2.48$ & - & 1 & reference & - \\
\hline $\mathrm{C} / \mathrm{C}$ & Negative & $40.60 \pm 2.04$ & 0.034 & 0.034 & $0.00-5.394$ & 0.191 \\
\hline
\end{tabular}

Note: p53 codon $72 \mathrm{G}$ is equivalent to $\mathrm{Arg}$ and $\mathrm{C}$ is equivalent to Pro. 
correlated with various clinical parameters and overall survival. However, Ma et al. [41] suggested that overexpression of p53 protein is related to poorer disease-free survival and a trend towards shorter time to progression, but not overall survival. In contrast, Masuda et al. [42] reported that p53 overexpression is associated with lower overall survival. Moreover, Wang and co-workers [43] demonstrated a significant association of $\mathrm{p} 53$ protein overexpression with locoregional recurrence of patients with NPC, but no impact on the 5-year survival rate. The present study also focused on p53 protein as a potential predictive marker of response to radiotherapy for locoregional NPC. Notably, expression of p53 protein was not affected by p53 codon 72 polymorphisms (Table 3 ). Moreover, no significant association was evident between p53 protein expression and PFS (Table 4). Nevertheless, patients expressing p53 showed poorer PFS among those diagnosed with locoregionally lymph node metastasis $(\mathrm{N}+)$ before treatment ( $p=0.032)$ (Figure $4 \mathrm{C})$. Our data indicate that a combination of positive p53 protein expression and local regional lymph node metastasis can be effectively used to predict poorer outcomes.

P21/waf1 has been described as a wild-type p53-inducible protein involved in inhibition of cell cycle progression through binding to cyclin/cyclin-dependent-kinase (CDK) complex. Earlier studies have provided evidence that after DNA damage, p53 enhances p21/waf1 transcription, which, in turn, inhibits the formation of cyclin-CDK complexes, blocking progression along the cell cycle in the G1-S transition stage [44]. 14-3-3 $\sigma$, a downstream target of $\mathrm{p} 53$, is upregulated in response to DNA damage, and acts as a negative regulator of cell cycle $\mathrm{G} 2-\mathrm{M}$ phase checkpoint. Moreover, 14-3-3 $\sigma$ interacts with p53 and positively potentiates its activity [45]. Yang et al. [46] found that overexpression of 14-3-3 $\sigma$ in NPC cells inhibits cell growth, sensitizes cells to apoptosis, counteracts Akt oncogenic signaling, and reduces tumorigenicity in nude mice. The function of $14-3-3 \sigma$ as a potential tumor suppressor gene in NPC was similarly confirmed by Yi et al. [47]. Accordingly, we attempted to determine whether the predictive effect of p53 codon 72 polymorphism is correlated with p21 and 14-3-3 $\sigma$ expression. In our experiments, p21 and 14-3-3 $\sigma$ protein levels were not affected by p53 codon 72 polymorphisms. Based on this finding, we propose that the predictive value of p53 codon72 in response to radiotherapy for NPC is not associated with the regulation of downstream proteins, $\mathrm{p} 21$ and 14-3-3 $\sigma$.

The PI3K/Akt pathway plays an essential role in the transcriptional activation functions of $\mathrm{p} 53$, thereby modulating cell fate decisions. Retrospective studies by Schuurbiers et al. [48] showed that pAkt expression is an independent prognostic indicator of clinical outcomes of lung cancer. Yip et al. [17] reported that Akt is activated in $42.2 \%$ and 35.9\% NPC cases, based on pAkt (Thr308) and pAkt
(Ser473) immunoreactivity, respectively. The group further demonstrated that pAkt promotes cell proliferation and survival and is critical in NPC pathogenesis. In the present study, positive expression of pAkt (Thr308) protein was detected in $48.53 \%(33 / 72)$ of the subjects. No significant association between pAkt and PFS was observed. However, pAkt protein expression appeared to affect the relationship between p53 codon72 polymorphisms and outcomes in NPC patients. Subjects carrying the p53 codon72 Pro/Pro genotype showed longer time to disease progression, compared to patients with other genotypes $(p=0.043$, Figure $4 \mathrm{~A})$. This result was significant among subgroups with negative pAkt protein expression $(p=0.034$, Figure 4B), while no significant association between p53 codon 72 polymorphisms and PFS was found in the pAkt-positive subgroup. According to Ogawara et al., both Akt expression and serum treatment increase MDM2 ubiquitination of p53 [20]. It has been reported that p53 phosphorylated at Ser-20 escapes degradation by Mdm2, leading to stabilization of the protein [49]. Ozeki et al. confirmed that Mdm2-mediated degradation of 72Arg-p53 is diminished, compared to 72Pro-p53, which is at least partly attributable to higher levels of Ser-20 phosphorylation in p53-72R [50]. One possibility is that 72Pro-p53 is more easily down regulated via activation of the PI3K/Akt pathway, compared to 72Arg-p53. Therefore, the PI3K-Akt pathway may contribute to cell fate determination via selective inhibition of 72Pro-p53 accumulation. As a result, the p53 codon72 Pro/Pro carriers show no superiority in terms of response to radiotherapy in the pAkt-positive subgroup.

Our data collectively suggest that the p53 codon72 Pro/ Pro genotype of the p53 gene in locoregional NPC is a useful prognostic marker for identifying the patient populations that respond poorly to radiotherapy, particularly in those negative for pAkt expression.

\section{Conclusions}

We have shown that the p53 codon72 Pro/Pro genotype presents an independent predictor of better outcome in locoregional NPC patients. Positive expression of pAkt appears to act as a suppressor of this predictive function of the p53 codon72 Pro/Pro genotype. We observed no involvement of p21 and 14-3-3 $\sigma$ expression in the mechanism underlying the predictive value of p53 codon 72 in response to radiotherapy in NPC. In addition, our results indicate that a combination of positive p53 protein expression and local regional lymph node metastasis may effectively act as a positive predictor of high risk of disease progression.

\section{Grant support}

Science Foundation for Post Doctorate Research from the China Hunan Provincial Science and Technology Department (No.: 2012RS4011). 


\section{Competing interests}

The authors declare that they have no competing interests.

\section{Authors' contributions}

$X X, H W, B H$, and $J L$ carried out the projects design and paper writing. $\mathrm{HJ}$, SO, and $X X$ carried out the collection of clinic data. XX, HW, JH carried out the immunohistochemical studies. XX, HW, JZ and YZ carried out the DNA amplification and genotyping. All authors read and approved the final manuscript.

\section{Author details}

'Department of Radiation and Oncology, Hunan Provincial Tumor Hospital \& Affiliated Tumor Hospital of Xiangya Medical School, Central South University, Changsha 410013, China. ${ }^{2}$ Department of Radiation and Oncology, Xianya Hospital, Central South University, Changsha, China. ${ }^{3}$ Department of Pathology, Hunan Provincial Tumor Hospital \& Affiliated Tumor Hospital of Xiangya Medical School, Central South University, Changsha, China.

\section{Received: 22 December 2012 Accepted: 6 May 2013}

Published: 11 May 2013

\section{References}

1. Min HQ: Nasopharyngeal carcinoma. In Epidemiology. Edited by Gun GY. Beijing, China: People's Medical Press; 1996:280-285.

2. Huncharek M, Kupelnick B: Combined chemoradiation versus radiation therapy alone in locally advanced nasopharyngeal carcinoma:results of ameta-analysis of 1,528 patients from six randomized trials. Am J Clin Oncol 2002, 25:219-223.

3. Langendijk JA, Leemans CR, Buter J, Berkhof J, Slotman BJ: The additional value of chemotherapy to radiotherapy in locally advanced nasopharyngeal carcinoma: a meta-analysis of the published literature. J Clin Oncol 2004, 22:4604-4612.

4. Thomas M, Kalita A, Labrecque S, Pim D, Banks L, Matlashewski G: Two polymorphic variants of wild-type p53 differ biochemically and biologically. Mol Cell Biol 1999, 19:1092-1100.

5. Dumont $P$, Leu J, Della Pietra AC 3rd, George DL, Murphy M: The codon 72 polymorphic variants of p53 have markedly different apoptotic potential. Nat Genet 2003, 33:357-365.

6. Sullivan A, Syed N, Gasco M, Bergamaschi D, Trigiante G, Attard M, Hiller L, Farrell PJ, Smith P, Lu X, Crook T: Polymorphism in wild-type p53 modulates response to chemotherapy in vitro and in vivo. Oncogene 2004, 23:3328-3337

7. Pim D, Banks L: 553 polymorphic variants at codon 72 exert different effects on cell cycle progression. Int J Cancer 2004, 108:196-199.

8. Bergamaschi D, Samuels Y, Sullivan A, Zvelebil M, Breyssens H, Bisso A, Del Sal G, Syed N, Smith P, Gasco M, Crook T, Lu X: iASPP preferentially binds p53 proline-rich region and modulates apoptotic function of codon 72-polymorphic p53. Nat Genet 2006, 38:1133-1141.

9. Fan R, Wu MT, Miller D, Wain JC, Kelsey KT, lencke JK, Christiani DC: The p53 codon 72 polymorphism and lung cancer risk. Cancer Epidemiol Biomarkers Prev 2000, 9:1037-1042.

10. Sakiyama T, Kohno T, Mimaki S, Ohta T, Yanagitani N, Sobue T, Kunitoh H, Saito R, Shimizu K, Hirama C, Kimura J, Maeno G, Hirose H, Eguchi T, Saito D, Ohki M, Yokota J: Association of amino acid substitution polymorphisms in DNA repair genes TP53, POLI, REV1 and LIG4 with lung cancer risk. Int J Cancer 2005, 114:730-737.

11. Boldrini L, Gisfredi S, Ursino S, Lucchi M, Greco G, Mussi A, Fontanini G: Prognostic impact of p53 Pro72 homozygous genotype in non-small cell lung cancer patients. Oncol Rep 2008, 19:771-773.

12. Tommiska J, Eerola H, Heinonen M, Salonen L, Kaare M, Tallila J, Ristima"ki A, Von Smitten K, Aittoma"ki K, Heikkila" P, Blomqvist C, Nevanlinna H: Clin. Breast cancer patients with p53 Pro72 homozygous genotype have a poorer survival. Clin Cancer Res 2005, 11:5098-5103.

13. Vannini I, Zoli W, Tesei A, Rosetti M, Sansone P, Storci G, Passardi A, Massa I, Ricci M, Gusolfino D, Fabbri F, Ulivi P, Brigliadori G, Amadori D: Bonafe M : Role of p53 codon 72 arginine allele in cell survival in vitro and in the clinical outcome of patients with advanced breast cancer. Tumor Biol 2008, 29:145-151.

14. Kim JG, Sohn SK, Chae YS, Song HS, Kwon KY, Do YR, Kim MK, Lee KH, Hyun MS, Lee WS, Sohn CH, Jung JS, Kim GC, Chung HY, Yu W: TP53 codon 72 polymorphism associated with prognosis in patients with advanced gastric cancer treated with paclitaxel and cisplatin. Cancer Chemother Pharmacol 2009, 64:355-360.

15. Zhuo XL, Cai L, Xiang ZL, Zhuo WL, Wang Y, Zhang XY: TP53 codon 72 polymorphism contributes to nasopharyngeal cancer susceptibility: a meta-analysis. Arch Med Res 2009, 40:299-305.

16. Jung IL, Kang HJ, Kim KC, Kim IG: PTEN/pAkt/p53 signaling pathway correlates with the radioresponse of non-small cell lung cancer. Int J Mol Med 2010, 25:517-523.

17. Yip WK, Leong VC, Abdullah MA, Yusoff S, Seow HF: Overexpression of phospho-Akt correlates with phosphorylation of EGF receptor, FKHR and BAD in nasopharyngeal carcinoma. Oncol Rep 2008, 19:319-328.

18. Levine AJ, Feng Z, Mak TW, You H, Jin S: Coordination and communication between the $\mathrm{p} 53$ and IGF-1-AKT-TOR signal transduction pathways. Genes Dev 2006, 20:267-275.

19. Gottlieb TM, Leal JF, Seger R, Taya Y, Oren M: Cross-talk between Akt, p53 and Mdm2: possible implications for the regulation of apoptosis. Oncogene 2002, 21:1299-1303.

20. Ogawara Y, Kishishita S, Obata T, Isazawa Y, Suzuki T, Tanaka K, Masuyama N, Gotoh Y: Akt enhances Mdm2-mediated ubiquitination and degradation of p53. J Biol Chem 2002, 277:21843-21850.

21. Meek DW: The p53 response to DNA damage. DNA Repair (Amst) 2004, 3:1049-1056.

22. Boehme KA, Kulikov R, Blattner C: $p 53$ stabilization in response to DNA damage requires Akt/PKB and DNA-PK. Proc Natl Acad Sci USA 2008, 105:7785-7790.

23. Suvasini R, Somasundaram K: Essential role of PI3-kinase pathway in p53-mediated transcription: Implications in cancer chemotherapy. Oncogene Oncogene 2010, 29:3605-3618.

24. Huang WC, Chen CC: Akt phosphorylation of p300 at Ser-1834 is essential for its histone acetyltransferase and transcriptional activity. Mol Cell Biol 2005, 25:6592-6602.

25. Hara A, Okayasu I: Cyclooxygenase-2 and inducible nitric oxide synthase expression in human astrocytic gliomas: correlation with angiogenesis and prognostic significance. Acta Neuropathol 2004, 108:43-48.

26. Salvioli S, Bonafe M, Barbi C, Storci G, Trapassi C, Tocco F, Gravina S, Rossi M, Tiberi L, Mondello C, Monti D, Franceschi C: p53 codon 72 alleles influence the response to anticancer drugs in cells from aged people by regulating the cell cycle inhibitor p21WAF1. Cell Cycle 2005, 4:1264-1271.

27. Den Reijer PM, Maier AB, Westendorp RG, Van Heemst D: Influence of the TP53 codon 72 polymorphism on the cellular responses to $X$-irradiation in fibroblasts from nonagenarians. Mech Ageing Dev 2008, 129:175-182.

28. Landers JE, Cassel SL, George DL: Translational enhancement of mdm2 oncogene expression in human tumor cells containing a stabilized wild-type p53 protein. Cancer Res 1997, 57:3562-3568.

29. Bergamaschi D, Gasco M, Hiller L, Sullivan A, Syed N, Trigiante G, Yulug I, Merlano M, Numico G, Comino A, Attard M, Reelfs O, Gusterson B, Bell AK, Heath V, Tavassoli M, Farrell PJ, Smith P, Lu X, Crook T: p53 polymorphism influences response in cancer chemotherapy via modulation of p73-dependent apoptosis. Cancer Cell 2003, 3:387-402.

30. Marin MC, Jost CA, Brooks LA, Irwin MS, O'Nions J, Tidy JA, James N, McGregor JM, Harwood CA, Yulug IG, Vousden KH, Allday MJ, Gusterson B, Ikawa S, Hinds PW, Crook T, Kaelin WG Jr: A common polymorphism acts as an intragenic modifier of mutant p53 behaviour. Nat Genet 2000, 25:47-54.

31. Tada M, Furuuchi K, Kaneda M, Matsumoto J, Takahashi M, Hirai A, Mitsumoto $Y$, Iggo RD, Moriuchi $\mathrm{T}$ : Inactivate the remaining p53 allele or the alternate $\mathrm{p} 73$ ? Preferential selection of the Arg72 polymorphism in cancers with recessive p53 mutants but not transdominant mutants. Carcinogenesis 2001, 22:515-517.

32. Lo KW, Huang DP: Genetic and epigenetic changes in nasopharyngeal carcinoma. Semin Cancer Biol 2002, 12:451-462.

33. Storey A, Thomas M, Kalita A, Harwood C, Gardiol D, Mantovani F, Breuer J, Leigh IM, Matlashewski G, Banks L: Role of a p53 polymorphism in the development of human papilloma-virus-associated cancer. Nature 1998, 393:229-234.

34. Lopez-Lizarraga E, Sanchez-Corona J, Montoya-Fuentes H, Bravo-Cuellar A, Campollo-Rivas O, Lopez-Demerutis E, Morgan-Villela G, Arcaute-Velazquez F, Monreal-Martinez JA: Human papillomavirus in tonsillar and nasopharyngeal carcinoma: isolation of HPV subtype 31. Ear Nose Throat J 2000, 79:942-944. 
35. Mirzamani N, Salehian P, Farhadi M, Tehran EA: Detection of EBV and HPV in nasopharyngeal carcinoma by in situ hybridization. Exp Mol Pathol 2006, 81:231-234.

36. Maxwell JH, Kumar B, Feng FY, McHugh JB, Cordell KG, Eisbruch A, Worden FP. Wolf GT, Prince ME, Moyer JS, Teknos TN, Chepeha DB, Stoerker J, Walline H, Carey TE, Bradford CR: HPV-positive/p16-positive/EBV-negative nasopharyngeal carcinoma in white North Americans. Head Neck 2010, 32:562-567.

37. Faccioli S, Cavicchi O, Caliceti U, Rinaldi Ceroni A, Chieco P: Cell proliferation as an independent predictor of survival for patients with advanced nasopharyngeal carcinoma. Mod Pathol 1997, 10:884-894.

38. Genc E, Hosal AS, Gedikoglu G, Ozyar E, Sozeri B: Prognostic value of p53, proliferating cell nuclear antigen, and Ki-67 expression in undifferentiated nasopharyngeal carcinomas. Otolaryngol Head Neck Surg 2000, 122:868-873.

39. Shi W, Pataki I, MacMillan C, Pintilie M, Payne D, O'Sullivan B, Cummings BJ, Warde P, Liu FF: Molecular pathology parameters in human nasopharyngeal carcinoma. Cancer 2002, 94:1997-2006.

40. Tsai ST, Jin YT, Leung HW, Wang ST, Tsao CJ, Su IJ: BCl-2 and proliferating cell nuclear antigen (PCNA) expression correlates with subsequent local recurrence in nasopharyngeal carcinomas. Anticancer Res 1998, 18:2849-2854

41. Ma BB, Poon TC, To KF, Zee B, Mo FK, Chan CM, Ho S, Teo PM, Johnson PJ, Chan AT: Prognostic significance of tumor angiogenesis, Ki 67, p53 oncoprotein, epidermal growth factor receptor and HER2 receptor protein expression in undifferentiated nasopharyngeal carcinoma-a prospective study. Head Neck 2003, 25:864-872.

42. Masuda M, Shinokuma A, Hirakawa N, Nakashima T, Komiyama S: Expression of bcl-2-, p53, and Ki-67 and outcome of patients with primary nasopharyngeal carcinomas following DNA-damaging treatment. Head Neck 1998, 20:640-644.

43. Wang LF, Chai CY, Kuo WR, Tai CF, Lee KW, Ho KY: The prognostic value of proliferating cell nuclear antigen (PCNA) and p53 protein expression in patients with advanced nasopharyngeal carcinoma. Acta Otolaryngol 2006, 126:769-774

44. Kouvidou C, Stefanaki K, Dai Y, Tzardi M, Koutsoubi K, Darivianaki K: P21/waf1 protein expression in nasopharyngeal carcinoma. Comparative study with PCNA, p53 and MDM-2 protein expression. Anticancer Res 1997, 17:2615-2619.

45. Yang $\mathrm{HY}$, Wen $\mathrm{YY}$, Chen $\mathrm{CH}$, Lozano G, Lee MH: 14-3-3 sigma positively regulates p53 and suppresses tumor growth. Mol Cell Biol 2003, 23:7096-7107.

46. Yang $H$, Zhao R, Lee MH: 14-3-3sigma, a p53 regulator, suppresses tumo growth of nasopharyngeal carcinoma. Mol Cancer Ther 2006, 5:253-860.

47. Yi B, Tan SX, Tang CE, Huang WG, Cheng AL, Li C, Zhang PF, Li MY, Li JL, Y $H$, Peng F, Chen ZC, Xiao ZQ: Inactivation of 14-3-3 sigma by promoter methylation correlates with metastasis in nasopharyngeal carcinoma. J Cell Biochem 2009, 106:858-866.

48. Schuurbiers OC, Kaanders JH, van der Heijden HF, Dekhuijzen RP, Oyen WJ Bussink J: The PI3-K/AKT-pathway and radiation resistance mechanisms in non-small cell lung cancer. J Thorac Oncol 2009, 4:761-767.

49. Bode AM, Dong Z: Post-translational modification of $\mathrm{p} 53$ in tumorigenesis. Nat Rev Cancer 2004, 4:793-805.

50. Ozeki C, Sawai Y, Shibata T, Kohno T, Okamoto K, Yokota J, Tashiro F, Tanuma S, Sakai R, Kawase T, Kitabayashi I, Taya Y, Ohki R: Cancer susceptibility polymorphism of $\mathrm{p} 53$ at codon 72 affects phosphorylation and degradation of p53 protein. J Biol Chem 2011, 286:18251-18260.

\section{Submit your next manuscript to BioMed Central and take full advantage of:}

- Convenient online submission

- Thorough peer review

- No space constraints or color figure charges

- Immediate publication on acceptance

- Inclusion in PubMed, CAS, Scopus and Google Scholar

- Research which is freely available for redistribution

Submit your manuscript at www.biomedcentral.com/submit
Biomed Central 